\title{
Magnetic fluid hyperthermia enhances cytotoxicity of bortezomib in sensitive and resistant cancer cell lines
}

This article was published in the following Dove Press journal:

International Journal of Nanomedicine

20 December 2013

Number of times this article has been viewed

\author{
Merlis P Alvarez-Berríos' \\ Amalchi Castillo' \\ Carlos Rinaldi ${ }^{1-3}$ \\ Madeline Torres-Lugo' \\ 'Department of Chemical Engineering, \\ University of Puerto Rico, Mayagüez, \\ Puerto Rico; ${ }^{2} \mathrm{C}$ Crayton Pruitt \\ Family Department of Biomedical \\ Engineering, ${ }^{3}$ Department of Chemical \\ Engineering, University of Florida, \\ Gainesville, FL, USA
}

\begin{abstract}
The proteasome inhibitor bortezomib (BZ) has shown promising results in some types of cancer, but in others it has had minimal activity. Recent studies have reported enhanced efficacy of BZ when combined with hyperthermia. However, the use of magnetic nanoparticles to induce hyperthermia in combination with BZ has not been reported. This novel hyperthermia modality has shown better potentiation of chemotherapeutics over other types of hyperthermia. We hypothesized that inducing hyperthermia via magnetic nanoparticles (MFH) would enhance the cytotoxicity of BZ in BZ-sensitive and BZ-resistant cancer cells more effectively than hyperthermia using a hot water bath (HWH). Studies were conducted using BZ in combination with MFH in two BZ-sensitive cell lines (MDA-MB-468, Caco-2), and one BZ-resistant cell line (A2780) at two different conditions, ie, $43^{\circ} \mathrm{C}$ for 30 minutes and $45^{\circ} \mathrm{C}$ for 30 minutes. These experiments were compared with combined application of HWH and BZ. The results indicate enhanced potentiation between hyperthermic treatment and BZ. MFH combined with BZ induced cytotoxicity in sensitive and resistant cell lines to a greater extent than HWH under the same treatment conditions. The observation that MFH sensitizes BZ-resistant cell lines makes this approach a potentially effective anticancer therapy platform.
\end{abstract}

Keywords: magnetic fluid hyperthermia, hot water hyperthermia, BZ, enhanced cytotoxicity, thermal sensitization

\section{Introduction}

The proteasome, a multisubunit proteinase machinery, is in charge of degrading $80 \%-90 \%$ of all nuclear and cytosolic proteins in cells ${ }^{1-3}$ and plays an essential role in regulating the intracellular concentration of specific proteins, thereby maintaining homeostasis within the cell. ${ }^{1,4,5}$ Inhibition of the $26 \mathrm{~S}$ proteasome prevents this targeted proteolysis, which can affect multiple signaling cascades within the cell, leading to cell death. ${ }^{1,6}$ As such, proteasome inhibition has become an attractive target for cancer treatment.

Bortezomib (BZ), a drug approved by the US Food and Drug Administration, is a reversible inhibitor of the chymotrypsin-like activity of the $26 \mathrm{~S}$ proteasome in mammalian cells. It has been tested as a potential therapeutic agent for the treatment of several types of cancer including breast, colon, ovarian, lung, and certain hematologic neoplasms. ${ }^{8}$ Unfortunately, some of these types of cancer do not respond to its therapeutic effect, because they have intrinsic or acquired BZ resistance. ${ }^{9-13}$ The reason for this phenomenon is still unknown, but some molecular mechanisms have been proposed. de Wilt et al demonstrated that intrinsic BZ resistance of non-small-cell lung cancer is related to increased proteasome activity. ${ }^{14}$ On the other hand, acquired resistance
Correspondence: Madeline Torres-Lugo Department of Chemical Engineering, University of Puerto Rico, Mayaguez Campus, PO Box 9000 , Mayaguez 0068I, Puerto Rico Tel +l 7878324040 ext 2585 Fax +l 7878343655

Email madeline@ece.uprm.edu 
was associated with mutation of the $\beta 5$ subunit, which is the proteasome subunit where BZ binds. ${ }^{14}$ Overexpression of antiapoptotic protein Bcl-2 and heat-shock proteins 27 , 70 , and 90 is also considered a mechanism of acquired BZ resistance. ${ }^{15,16}$

Recent studies have provided evidence of enhanced efficacy of BZ when used in combination with hyperthermia. ${ }^{11,17-19}$ $\mathrm{Xu}$ et al showed that hyperthermia using a water bath sensitized resistant breast cancer cells to BZ, resulting in enhanced cell death. ${ }^{11}$ Similar observations were made with HT1080, HeLa, H1299, and HCT116 cells exposed to BZ and hyperthermia. ${ }^{18,19}$ The mechanism by which hyperthermia enhances BZ cytotoxicity has not been elucidated. However, protein unfolding and subsequent aggregation induced by hyperthermia is considered one of the mechanisms by which hyperthermia sensitizes cells to proteasome inhibition. ${ }^{20}$

Although in vitro studies of hyperthermia with BZ have shown promising results, translation to the clinic has been limited due to challenges regarding application of hyperthermia as a treatment modality. These include avoidance of nonspecific damage to adjacent tissues, occurrence of tachycardia and malaise, and a detrimental impact on tissue metabolism, blood flow, organ function, and tissue repair. ${ }^{21,22}$ For these reasons, alternative hyperthermia application approaches are being actively pursued.

The use of magnetic nanoparticles for localized thermal oncotherapy is a novel and attractive approach. ${ }^{23}$ This approach, commonly called magnetic fluid hyperthermia (MFH), takes advantage of the deposition of thermal and mechanical energy by magnetic particles under an applied alternating magnetic field, resulting in local heating of cancerous tissue. ${ }^{24}$ Recently, we have demonstrated that application of MFH to treat a human epithelial colorectal adenocarcinoma cell line (Caco-2) was more effective in reducing cell viability when compared with hot water hyperthermia (HWH) at similar thermal doses. ${ }^{25}$ Also, combination treatment using cisdiamminedichloroplatinum(II) and $\mathrm{MFH}$ induced significant cytotoxicity in the Caco- 2 cell model, and was more effective than a combination of the drug with hyperthermia using a hot water bath. ${ }^{26}$ Subsequently, it was demonstrated that one of the mechanisms explaining why $\mathrm{MFH}$ is significantly more effective in combination with cisdiamminedichloroplatinum(II) than $\mathrm{HWH}$ is an increase in membrane fluidity which allows higher intracellular drug accumulation. ${ }^{27}$

Our past work motivated us to search for other anticancer drugs that could potentially be enhanced by the application of $\mathrm{MFH}$, particularly in cases of intrinsic or acquired chemoresistance. Given the expectation that delivery of thermal energy to the interior of a cell could result in enhanced protein denaturation, we hypothesized that proteasome inhibitors in combination with MFH should possess enhanced cytotoxicity that is greater than each individual treatment. In order to test this hypothesis, dose response curves and proteasome activity curves, as a function of BZ concentration were conducted. The following cell lines were selected to conduct the experiments: human epithelial breast carcinoma cells (MDA-MB-468), heterogeneous human colorectal adenocarcinoma cells derived from colon carcinoma (Caco-2), and human epithelial ovarian cancer cells established from the tumor tissue of an untreated patient (A2780). Two of these are BZ-sensitive (MDA-MB-468, Caco-2) and one is BZ-resistant (A2780). The cell response to $\mathrm{BZ}$ in combination with $\mathrm{MFH}$ at two different conditions $\left(43^{\circ} \mathrm{C}\right.$ for 30 minutes and $45^{\circ} \mathrm{C}$ for 30 minutes) was then measured and the combined cytotoxicity was compared with that of HWH and BZ. Results indicated that enhancement of cytotoxicity between MFH and BZ is greater than the effect produced by $\mathrm{HWH}$ and BZ at similar thermal doses. Our results confirm the effectiveness of $\mathrm{MFH}$ for potentiation of $\mathrm{BZ}$, even in cell lines that show intrinsic resistance to this drug, making this an attractive approach for enhancing the effectiveness of a drug already approved by the US Food and Drug Administration.

\section{Materials and methods Cell culture}

MDA-MB-468 and Caco-2 cells were obtained from the American Type Culture Collection (Manassas, VA, USA). The cells were cultured in $75 \mathrm{~cm}^{2}$ flasks (Costar, Corning, NY, USA) using Dulbecco's modified Eagle's medium (Sigma, St Louis, MO, USA) containing 10\% fetal bovine serum (Invitrogen, Carlsbad, CA, USA), 1\% nonessential amino acids (Invitrogen), 100 units/mL of penicillin (Sigma), and $100 \mu \mathrm{g} / \mathrm{mL}$ of streptomycin (Sigma), and supplemented with $2 \mathrm{mM}$ L-glutamine and $24 \mathrm{mM}$ sodium bicarbonate. The cells were maintained at $37^{\circ} \mathrm{C}, 95 \%$ relative humidity, and $5 \% \mathrm{CO}_{2}$. A2780 cells were donated by Dr Anil K Sood from the MD Anderson Cancer Center, Houston, TX, USA. They were cultured in Roswell Park Memorial Institute medium (Sigma) with $15 \%$ fetal bovine serum and $0.1 \%$ gentamicin (Sigma) at $37^{\circ} \mathrm{C}$ under $5 \% \mathrm{CO}_{2}$.

\section{Drug}

BZ (LC Laboratories, Woburn, MA, USA) was dissolved in dimethylsulfoxide (Sigma), aliquoted, and stored at $-20^{\circ} \mathrm{C}$. 
Aliquots were thawed and diluted in Dulbecco's modified Eagle's medium before use.

\section{Synthesis of iron oxide nanoparticles}

Iron oxide nanoparticles were synthesized by the coprecipitation method and coated with carboxymethyl dextran, as described previously. ${ }^{28}$ An aqueous iron solution $\left(\mathrm{Fe}^{+3}: 2 \mathrm{Fe}^{+2}\right)$ and an ammonium hydroxide solution were mixed at $80^{\circ} \mathrm{C}$. The $\mathrm{pH}$ of this reaction mixture was maintained at 8.0 while stirring for one hour with bubbling nitrogen. After this reaction period, the solution was centrifuged at 1,500 rpm for 5 minutes, the supernatant was discarded, and the magnetic nanoparticles were peptized with tetramethyl ammonium hydroxide (1 M). The peptized nanoparticles were dried at $65^{\circ} \mathrm{C}$ using a vacuum oven. Next, $1.125 \mathrm{~g}$ of peptized iron oxide nanoparticles were functionalized with 3-aminopropyltriethoxysilane (APS) in a solution containing $75 \mathrm{~mL}$ dimethylsulfoxide, $5 \mathrm{~mL}$ of APS, $1.25 \mathrm{~mL}$ of water, and $100 \mu \mathrm{L}$ of acetic acid. This solution was stirred for 36 hours in a shaker at $150 \mathrm{rpm}$ and room temperature. At the end of the reaction, the nanoparticles were washed four times with ethanol by centrifugation and left to dry at room temperature. The iron oxide nanoparticles coated with APS were then functionalized with carboxymethyl dextran via reaction with N,N-(3-dimethylaminopropyl)-N'-ethylcarbodiimide hydrochloride (EDC)/N-hydroxysuccinimide (NHS) in order to form covalent bonds between APS and carboxymethyl dextran. This reaction was achieved by mixing a solution containing $1 \mathrm{~g}$ of carboxymethyl dextran, $10 \mathrm{~mL}$ of deionized water, $12.25 \mathrm{mg}$ of EDC, and $7.25 \mathrm{mg}$ of NHS at $\mathrm{pH} 4.5-5$ with $0.1 \mathrm{~g}$ of IO-APS dissolved in $10 \mathrm{~mL}$ of deionized water at $\mathrm{pH} 4.5-5$. This mixture was stirred at $150 \mathrm{rpm}$ for 36 hours at room temperature. After this reaction period, the nanoparticles were washed three times with ethanol by centrifugation and left to dry in a vacuum oven at $65^{\circ} \mathrm{C} .{ }^{29}$

The nanoparticles were sterilized at a temperature of $121^{\circ} \mathrm{C}$ and 15 psi for 60 minutes before the in vitro experiments. They were then characterized and suspended in Dulbecco's modified Eagle's medium prior to the experiments. The final particle concentration was $3.848 \mathrm{mg}$ particles per $\mathrm{mL}(0.5 \mathrm{mg} \mathrm{IO} / \mathrm{mL})$.

\section{Characterization of nanoparticles}

The physical size and morphology of the iron oxide nanoparticles were determined using an energy-filtered transmission electron microscope (LEO 922 Omega, Carl Zeiss Meditec AG, Jena, Germany) at $200 \mathrm{kV}$. The hydrodynamic diameter of the synthesized and functionalized nanoparticles suspended in deionized water was determined by dynamic light scattering using a particle size analyzer (BI-90 Plus, Brookhaven Instrument Corporation, Holtsville, NY, USA). Inorganic core content was estimated using a thermogravimetric analyzer (TGA/DSC1, Mettler Toledo Inc, Columbus, $\mathrm{OH}, \mathrm{USA})$. The magnetic properties of the nanoparticles were determined using a SQUID magnetometer (MPMS XL-7, Quantum Design Inc., San Diego, CA, USA). The specific absorption rate of the iron oxide nanoparticles was obtained by placing a solution of nanoparticles in deionized water at a concentration of $0.5 \mathrm{mg} \mathrm{IO} / \mathrm{mL}$ in an induction heater (HFI $3 \mathrm{KW}$ RF heating system, RDO Induction LLC, Washington, NJ, USA) with magnetic field intensities ranging from $24.18 \mathrm{kA} / \mathrm{m}$ to $34.73 \mathrm{kA} / \mathrm{m}$. The specific absorption rate is reported as watt per gram of iron oxide.

\section{$B Z$ dose-response curve}

MDA-MB-468 and Caco-2 cells were seeded in 96-well plates (Fisher Scientific, Suwanee, GA, USA) and allowed to adhere for 48 hours in Dulbecco's modified Eagle's medium solution. A2780 cells were allowed to adhere for 24 hours in Roswell Park Memorial Institute medium. These time periods were chosen to ensure that the cells were in log phase growth before treatment. After this incubation period, the cells were exposed to varying concentrations of BZ (2-1,000 nM) for 48 hours. The cells were then washed twice with phosphatebuffered saline (Sigma), stained with Cell Titer Blue ${ }^{\mathrm{TM}}$ (Promega, Madison, WI, USA) and analyzed fluorometrically (Spectra MAX Gemini EM, Molecular Devices, Sunnyvale, CA, USA).

\section{Proteasome activity}

Cells were seeded in 96-well plates (10,000 cells per well) and allowed to adhere in medium solution as described before. Adhered cells were exposed to various concentrations of BZ (2-1,000 nM) for 3 hours. Next, $100 \mu \mathrm{L}$ of ProteasomeGlo $^{\text {TM }}$ Chymotrypsin-Like Assay (Promega), containing a substrate which luminesces when recognized and degraded by the proteasome, was added per well and allowed to react at room temperature for 15 minutes in the dark. After this period, luminescence measurements were made in a spectrofluorometer (Spectra MAX Gemini EM).

\section{Combined hyperthermia treatment}

Approximately $5 \times 10^{5}$ cells were transferred to $10 \mathrm{~mL}$ glass tubes. Cells to be treated by HWH were suspended in $2.5 \mathrm{~mL}$ of complete medium with and without BZ. Next, samples in the presence of $\mathrm{BZ}$ were left in the incubator for 3 hours to promote proteasome inhibition before hyperthermic 
treatment. After pretreatment, the samples were placed in a temperature-regulated water bath for 30 minutes at $43^{\circ} \mathrm{C}$ or $45^{\circ} \mathrm{C}$. Cells to be treated by $\mathrm{MFH}$ were suspended in $2.5 \mathrm{~mL}$ of DMEM solution with or without BZ, concomitantly with a concentration of $3.8 \mathrm{mg} / \mathrm{mL}$ of autoclaved carboxymethyl dextran-coated magnetite nanoparticles. Samples containing BZ were incubated for 3 hours prior to applying the alternating magnetic field. The samples were then placed in an induction heater coil (HFI $3 \mathrm{KW} \mathrm{RF}$ heating system) and magnetically heated to $43^{\circ} \mathrm{C}$ or $45^{\circ} \mathrm{C}$ for 30 minutes. A magnetic field of $29.39 \mathrm{kA} / \mathrm{m}$ or 34.73 $\mathrm{kA} / \mathrm{m}$ was applied to maintain the sample temperature at $43^{\circ} \mathrm{C}$ or $45^{\circ} \mathrm{C}$, respectively. A frequency of $233 \mathrm{kHz}$ was applied at both temperature conditions. Control tubes had the same dimethylsulfoxide concentration as the experimental group $(0.1 \%)$ but remained in the incubator at $37^{\circ} \mathrm{C}$. After treatment, 100,000 cells were transferred to six-well plates (Fisher Scientific) exposing cells continuously to the drug to maintain a constant proteasome inhibition for an additional of 48 hours at $37^{\circ} \mathrm{C}$ and $5 \% \mathrm{CO}_{2}$. After incubation, the cells were trypsinized and cell viability was measured using the trypan blue exclusion method (Sigma). Our previous work using anticancer drugs such as cisplatin in combination with hyperthermia has shown similar tendencies between viability ratio and surviving fraction using trypan blue and clonogenic survival fraction respectively. For this reason, we only determined the viability ratio in this study.

\section{Statistical analysis}

Unless otherwise stated, the sample size was $n=3$. Statistical analyses were conducted using the Student's $t$-test (twotailed distribution, two samples with unequal variances). Differences were considered to be statistically significant at $P<0.05$.

\section{Results}

\section{Nanoparticle characterization}

The cluster size of the synthesized magnetic nanoparticles determined by transmission electron microscopy was approximately $69 \pm 4 \mathrm{~nm}$, consisting of primary nanoparticles $11 \mathrm{~nm}$ in diameter (Figure 1A shows a representative image of a cluster of particles). The hydrodynamic diameter of the iron oxide nanoparticles coated with carboxymethyl dextran determined by dynamic light scattering was $\sim 70 \mathrm{~nm}$ (Figure 1B), with some aggregates of $\sim 300 \mathrm{~nm}$ visible in the volume-weighted diameter distribution. The inorganic mass was determined by thermogravimetric analysis (Figure 1C), and was determined to be $14 \%$ by weight. The specific absorption rate of the nanoparticles was $46.9 \mathrm{~W} / \mathrm{g}$ of iron oxide at a magnetic field amplitude of $34.73 \mathrm{kA} / \mathrm{m}$ and frequency of $233 \mathrm{kHz}$. Finally, SQUID magnetization measurements showed the nanoparticles to be superparamagnetic, with a saturation magnetization of $\sim 58 \mathrm{Am}^{2} / \mathrm{kg}$ at $300 \mathrm{~K}$ (Figure 1D). The nanoparticles used in this study were not cytotoxic at a concentration of up to $0.5 \mathrm{mg} \mathrm{IO} / \mathrm{mL}$ (data not shown).

\section{Sensitivity of cancer cells to BZ}

Recent studies have shown that the sensitivity of cancer cells to BZ is cell line-dependent. ${ }^{8,9,12,13}$ To assess the sensitivity of different cancer cell lines to the therapeutic effect of BZ, the viability of three different cell lines (Caco-2, MDA-MB-468, and A2780) was determined after exposing the cells to increasing concentrations of BZ for 48 hours.

The Caco-2 and MDA-MB-468 cell lines were significantly more sensitive to BZ than A2780 cell lines, showing half maximal inhibitory concentrations of $15 \mathrm{nM}, 9 \mathrm{nM}$, and $250 \mathrm{nM}$, respectively (Figure 2). This result confirms that A2780 has intrinsic BZ resistance. For subsequent experiments, the maximum BZ concentration was kept at $100 \mathrm{nM}$, because this is the maximum concentration clinically achieved in the plasma of patients treated with BZ. ${ }^{13}$

\section{Proteasome activity curves}

$\mathrm{BZ}$ is a reversible proteasome inhibitor and a modified dipeptidyl boronic acid specifically designed to fit the active sites of the proteasome. ${ }^{9}$ Proteasome inhibition is a function of exposure time and concentration of the drug. To evaluate the effect of hyperthermia in combination with BZ for BZ-sensitive and BZ-resistant cells under the same conditions, it is necessary to choose a BZ concentration that achieves the same proteasome inhibition before applying hyperthermic treatment. Therefore, proteasome inhibition curves, as a function of $\mathrm{BZ}$ concentration, were determined by exposing cells to the drug for 3 hours. Proteasome activity was measured after this incubation period.

The proteasome activity curve for Caco-2 cells (Figure 3 ) illustrates that, above $10 \mathrm{nM} \mathrm{BZ}$, proteasome activity does not change further for this exposure time. Proteasome inhibition is approximately $57 \%$ at $6 \mathrm{nM} \mathrm{BZ}$. Proteasome activity also decreases in MDA-MB-468 and A2780 cell lines as a function of drug concentration. At $10 \mathrm{nM} \mathrm{BZ}$, the proteasome activity is $59 \%$ for MDA-MB-468, while for A2780 at $30 \mathrm{nM}$ the proteasome activity is $56 \%$. It was observed that A2780 cells showed greater proteasome activity than the other cell lines at a given concentration of BZ. In order to verify enhanced 

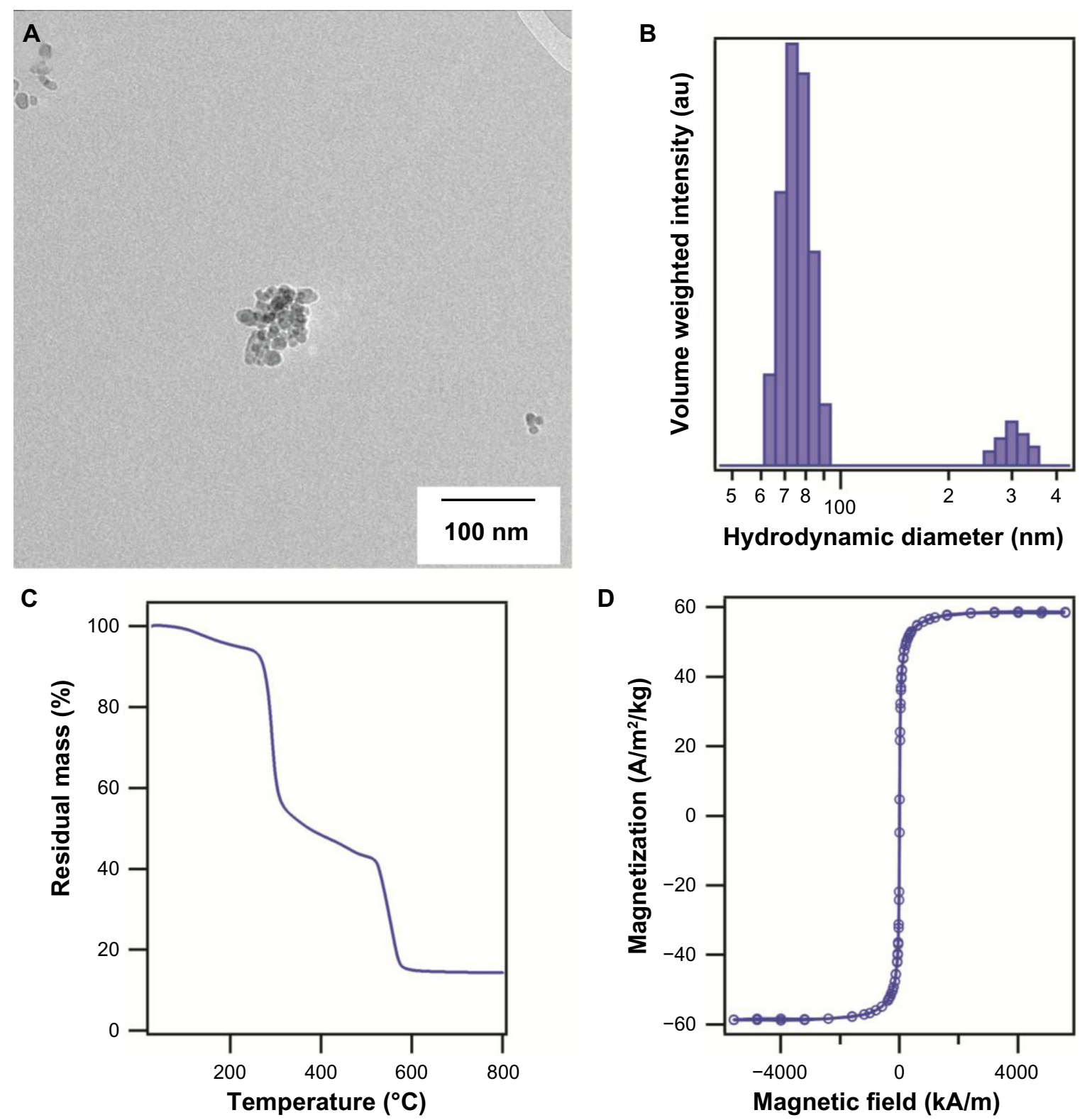

Figure I (A) Representative transmission electron microscopy image of magnetic nanoparticles synthesized by the coprecipitation method and coated with carboxymethyl dextran. (B) Volume-weighted hydrodynamic diameter distribution. (C) Remnant mass as a function of temperature for carboxymethyl dextran-coated iron oxide nanoparticles determined by thermogravimetric analysis. (D) Equilibrium magnetization as a function of field at room temperature.

cytotoxicity using BZ and hyperthermia in BZ-sensitive and BZ-resistant cells under the same conditions, for subsequent experiments we exposed cells to a lower drug concentration which produced approximately the same level of proteasome inhibition for a pre-exposure time of 3 hours in all cell lines. The concentrations used were $10 \mathrm{nM}, 6 \mathrm{nM}$, and $30 \mathrm{nM}$ for MDA-MB-468, Caco-2, and A2780 cells, respectively.

\section{Enhanced potentiation by MFH and} BZ in sensitive and resistant cells

Recent studies have reported enhanced potentiation using hyperthermia and proteasome inhibitors in cancer cells. ${ }^{18,30}$ In an effort to assess this enhanced cytotoxicity, studies using BZ in combination with MFH in two BZsensitive (MDA-MB-468, Caco-2) and one BZ-resistant (A2780) cancer cell line were performed and compared with potentiation using HWH. Cells were pretreated with $\mathrm{BZ}$ for 3 hours, followed by exposure to hyperthermic treatment for 30 minutes at $43^{\circ} \mathrm{C}$ or $45^{\circ} \mathrm{C}$. To achieve this, HWH samples were placed in a water bath at the target temperature for 30 minutes and MFH samples were placed in an alternating magnetic field of sufficient amplitude to achieve temperatures of $43^{\circ} \mathrm{C}(29.39 \mathrm{kA} / \mathrm{m})$ and $45^{\circ} \mathrm{C}(34.73 \mathrm{kA} / \mathrm{m})$ for 30 minutes. Experiments with 


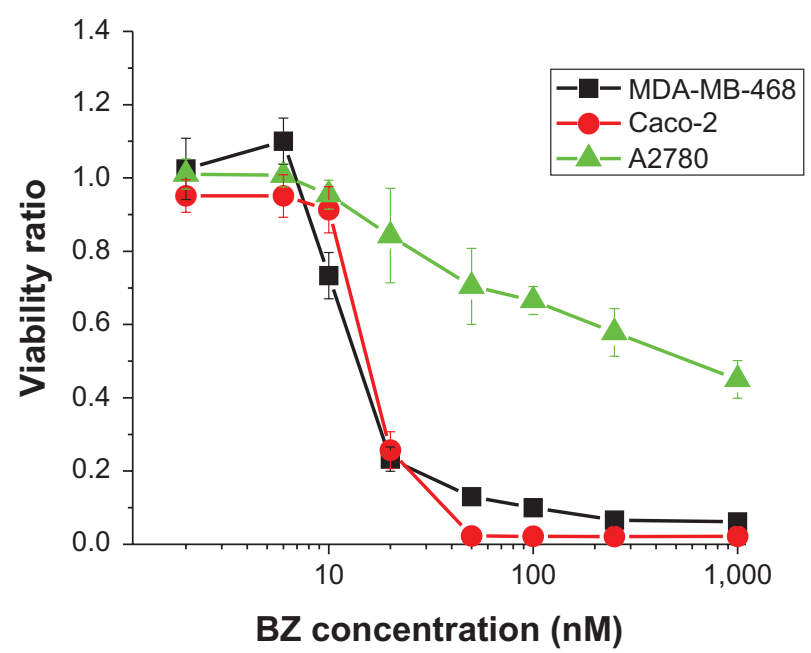

Figure 2 Dose-response curve for MDA-MB-468, Caco-2, and A2780 cell lines. Cells were exposed to BZ concentrations of $2-1,000 \mathrm{nM}$ for 48 hours. Error bars represent the standard error of eight independent experiments.

a similar target temperature had similar temperature-time profiles, hence the samples were subjected to similar thermal doses as quantified using the cumulative equivalent minutes dose metric of Dewey et al. ${ }^{31}$ After treatment, the cell samples were allowed to recover for a period of 48 hours. Cell viability was then measured by cell counting. BZ concentrations were chosen individually for each cell line based on the amount of drug that would result in similar proteasome inhibition ( $6 \mathrm{nM}$ for Caco-2, $10 \mathrm{nM}$ for MDA-MB-468, and $30 \mathrm{nM}$ for A2780).

Enhanced cytotoxicity was evident when BZ was combined with either type of hyperthermic treatment (Figure 4). Cell death was not observed when Caco-2 cells were exposed

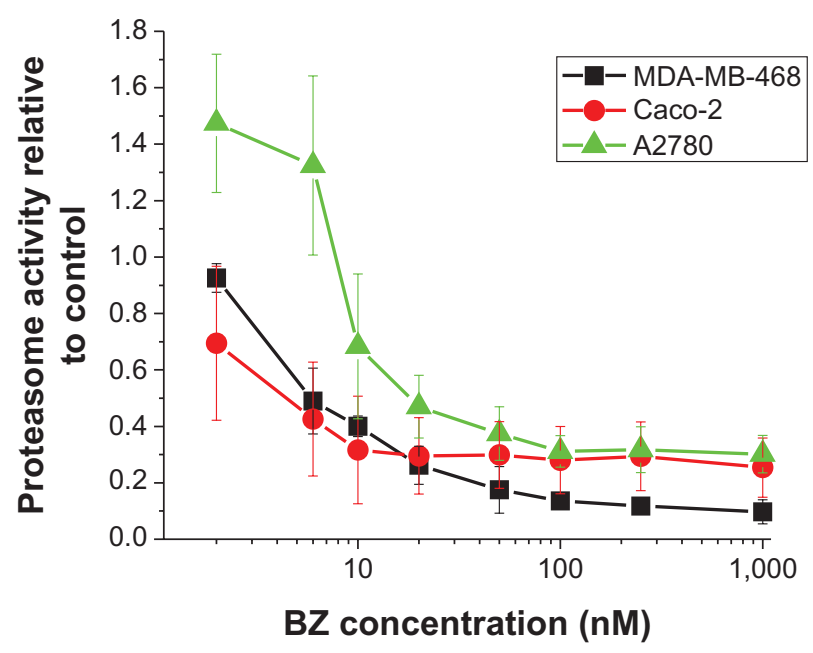

Figure 3 Proteasome activity for MDA-MB-468, Caco-2, and A2780 cell lines treated with different concentrations of $B Z(2-1,000 \mathrm{nM})$ for 3 hours of exposure time. Error bars represent the standard error of three independent experiments. to $6 \mathrm{nM} \mathrm{BZ}$ for as long as 48 hours at $37^{\circ} \mathrm{C}$ (Figure $4 \mathrm{~A}$ ). However, when BZ was combined with hyperthermia, this resulted in a significant decrease in cell viability, as shown by the results at $43^{\circ} \mathrm{C}(89 \% \pm 5.6 \%$ reduction for $\mathrm{BZ}+\mathrm{MFH}$ and $60 \% \pm 10 \%$ reduction for $\mathrm{BZ}+\mathrm{HWH}, P<0.05)$ and $45^{\circ} \mathrm{C}(\sim 99 \% \pm 1.2 \%$ reduction for $\mathrm{BZ}+\mathrm{MFH}$ and $94 \% \pm 2.3 \%$ reduction for $\mathrm{BZ}+\mathrm{HWH}, P<0.05)$. Consistent with prior observations, ${ }^{26} \mathrm{MFH}$ showed significantly more cell death than HWH for both temperature conditions. Similarly, both types of hyperthermia enhanced BZ cytotoxicity in MDAMB-468 cells (Figure 4B). Cells treated with MFH or HWH in combination with $\mathrm{BZ}$ showed more cell death when compared with cells treated with $\mathrm{BZ}$ alone at $37^{\circ} \mathrm{C}$. Again, MFH was significantly more effective in inducing cell death than $\mathrm{HWH}$ under the same temperature conditions, as shown by the results at $43^{\circ} \mathrm{C}(76 \% \pm 7 \%$ reduction for $\mathrm{BZ}+\mathrm{MFH}$ and $55 \% \pm 8 \%$ reduction for $\mathrm{BZ}+\mathrm{HWH}, P<0.05)$ and $45^{\circ} \mathrm{C}(\sim 88 \% \pm 2 \%$ reduction for MFH $+\mathrm{BZ}$ and $78 \% \pm 4 \%$ reduction for $\mathrm{HWH}+\mathrm{BZ}, P<0.05)$. Finally, as previously noted, A2780 cells were resistant to BZ, with approximately $60 \% \pm 4 \%$ of cells viable even at $100 \mathrm{nM} \mathrm{BZ}$ (Figure 2). At $30 \mathrm{nM} \mathrm{BZ}$ when treated in an incubator, these cells demonstrated no significant cytotoxic response. Interestingly, the effect of BZ was greatly enhanced in the presence of hyperthermia, with MFH treatment showing the greatest response (Figure $4 \mathrm{C})$. At $43^{\circ} \mathrm{C}$, cell death was evident $(91 \% \pm 4.9 \%$ reduction for $\mathrm{BZ}+\mathrm{MFH}$ and $70 \% \pm 10 \%$ reduction for $\mathrm{BZ}+$ HWH, $P<0.05$ ). However, when hyperthermia was applied for 30 minutes at $45^{\circ} \mathrm{C}$ to pretreated samples with $\mathrm{BZ}$, almost complete eradication of cell viability was observed $(\sim 99.7 \% \pm 0.6 \%$ reduction for $\mathrm{BZ}+\mathrm{MFH}$ and $98 \% \pm 0.5 \%$ reduction for $\mathrm{BZ}+\mathrm{HWH}, P<0.05)$. Taken together, these results demonstrate enhancement of cytotoxicity by BZ with hyperthermia in both sensitive and resistant cell lines and that MFH is more effective than $\mathrm{HWH}$ at enhancing BZ cytotoxicity under the same temperature conditions.

\section{Discussion}

Caco-2 and MDA-MB-468 cells exhibited greater sensitivity to $\mathrm{BZ}$, while $\mathrm{A} 2780$ showed a minimal response to $\mathrm{BZ}$, with half maximal inhibitory concentrations of $15 \mathrm{nM}, 9 \mathrm{nM}$, and $250 \mathrm{nM}$, respectively. This result suggests that the A2780 cell line possesses intrinsic BZ resistance, while Caco-2 and MDA-MB-468 are sensitive to the therapeutic effect of BZ. Although it was to be expected that the response to BZ would be cell type-dependent, this expectation had not been tested for Caco-2, MDA-MB-468, and A2780 cell lines before. This difference in sensitivity to proteasome inhibitors remains poorly 

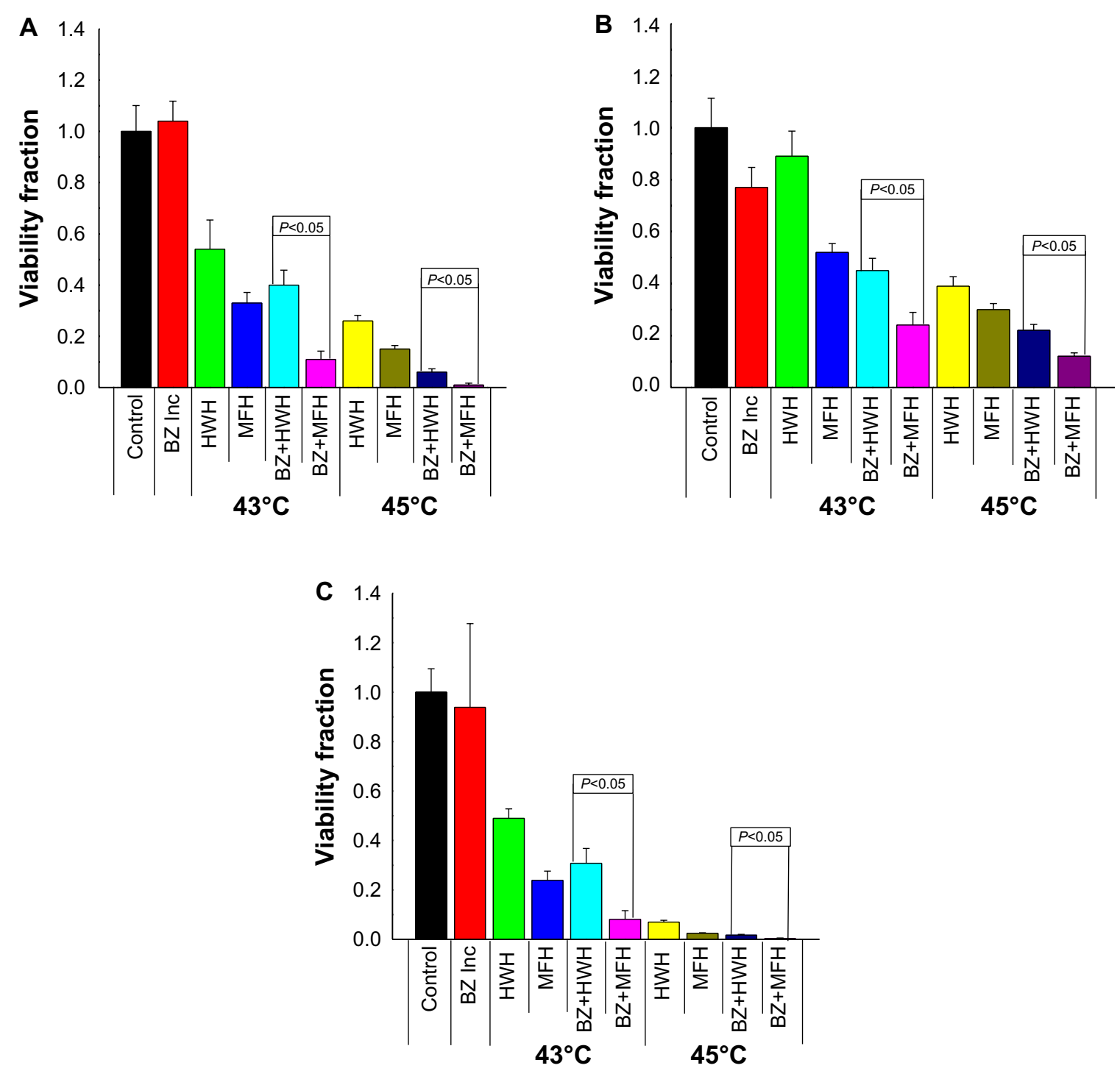

Figure 4 Viability ratio for $\mathrm{BZ}$-sensitive and $\mathrm{BZ}$-resistant cell lines pretreated for 3 hours with $\mathrm{BZ}$, exposed to hyperthermic treatment (MFH and $\mathrm{HWH}$ ) at $43^{\circ} \mathrm{C}$ and $45^{\circ} \mathrm{C}$ for 30 minutes, and incubated for a recovery period of 48 hours in the presence of BZ. (A) Caco-2 viability ratio using $6 \mathrm{nM}$ of BZ.(B) Viability ratio for MDA-MB-468 cell line using $10 \mathrm{nM}$ of BZ. (C) A2780 viability ratio using $30 \mathrm{nM}$ of BZ. Error bars represent the standard error of three independent experiments.

Abbreviations: Control, cells maintained in the incubator; $\mathrm{BZ}$ Inc, cells with $\mathrm{BZ}$ in incubator; $\mathrm{HWH}$, cells treated by hot water hyperthermia; $\mathrm{MFH}$, cells treated by magnetic fluid hyperthermia; BZ, bortezomib.

understood. However, some studies have reported that intrinsic BZ resistance is related to high proteasome activity, implying that BZ-resistant cell lines need a higher BZ concentration to produce the same proteasome inhibition compared with BZsensitive cell lines. ${ }^{14}$ For example, Xu et al demonstrated that the proteasome activity of BZ-sensitive cells was less than that of BZ-resistant cells under the same conditions. ${ }^{11}$

Proteasome activity curves were determined in order to assess the effect of BZ concentration in all the cell lines. Proteasome activity results revealed that the A2780 cell line, which is resistant to BZ as reported in Figure 2, demonstrated higher proteasome activity than the other two BZ-sensitive cell lines (Figure 3). This result is consistent with reports in the literature mentioned above. ${ }^{11}$

It is known that hyperthermia can sensitize cells to some anticancer drugs, thereby enhancing their efficacy. ${ }^{18,19,26,30}$ This has been attributed to cellular events triggered by hyperthermia, such as changes in membrane fluidity which produce alterations in intracellular drug concentration, cytoskeletal, lysosomal and endoplasmic reticulum changes, inhibition of repair enzymes, impairment of RNA/DNA synthesis, unfolding, and subsequent protein aggregation. ${ }^{20,32-34}$ The way in which hyperthermia is applied can intensify some of these cellular events. ${ }^{27,35}$ 
In this study, we tested the effect of hyperthermia induced in two different ways (using a water bath and using magnetic nanoparticles) in combination with BZ in cells sensitive and resistant to $\mathrm{BZ}$. To evaluate the effect of hyperthermia in combination with BZ under the same conditions, we used a BZ concentration that resulted in a similar proteasome inhibition in all cell lines prior to application of hyperthermia. Our results confirm that hyperthermia enhanced the effectiveness of the drug in all cell lines. We observed that MFH in combination with $\mathrm{BZ}$ produced more cell death than $\mathrm{HWH}$ under the same conditions. Although BZ-sensitive and BZ-resistant cells showed similar levels of proteasome inhibition, thermal sensitization induced by $\mathrm{MFH}$ in combination with BZ in cells resistant to BZ resulted in significant cell death.

The mechanisms of the enhanced cytotoxicity seen with $\mathrm{MFH}$ and $\mathrm{BZ}$ are yet to be elucidated. A recent study by our group demonstrated that MFH induced significant membrane fluidity with better subsequent intracellular accumulation of cisplatin. ${ }^{27}$ While the therapeutic effect of cisplatin is limited by transport into the cell, BZ does not appear to have this limitation. BZ has rapid effects on the cell, as shown by pharmacokinetic and pharmacodynamic evaluation. ${ }^{8}$ Additionally, several studies have suggested that BZ is not affected by the efflux pumps involved in multidrug resistance. ${ }^{36-39}$ However, it is possible that the membrane fluidity induced by MFH can enhance intracellular accumulation of BZ, and we will explore this possibility in future research.

It is known that hyperthermia $\left(40^{\circ} \mathrm{C}-46^{\circ} \mathrm{C}\right)$ causes proteins to unfold, exposing hydrophobic groups that can interact to form aggregates. ${ }^{20}$ Recent studies have shown that hyperthermia using a water bath interrupts protein homeostasis in the cell. ${ }^{18}$ Taking into account the fact that MFH produces marked effects on the cell as shown by recent studies, ${ }^{27,35}$ one potential cause of this enhanced cytotoxicity could be related to increased production of unfolded proteins and their subsequent aggregation induced by heat delivered by the magnetic nanoparticles, drastically affecting protein homeostasis.

Overall, our results are significant because they demonstrate the enhanced potential of MFH to sensitize resistant and nonresistant cancer cells to the drug BZ. Future work will explore possible causes of this enhanced potentiation, such as interruption of protein homeostasis, differences in uptake of magnetic nanoparticles, and morphologic changes induced by hyperthermic treatments.

\section{Conclusion}

Our findings demonstrate that combined treatment of BZ and $\mathrm{MFH}$ results in greater cell death in BZ-sensitive and
BZ-resistant cells, as compared with $\mathrm{MFH}$ or BZ alone, or $\mathrm{BZ}$ in combination with $\mathrm{HWH}$. The fact that MFH induced greater BZ cytotoxicity than $\mathrm{HWH}$ in BZ-sensitive and BZresistant cancer cell lines makes it an attractive method for inducing local hyperthermia without causing discomfort and the side effects associated with other types of hyperthermia. Additionally, the combination of MFH and BZ could enable treatment of cancers that are sensitive and resistant to the proteasome inhibitor BZ. We believe that this enhanced potentiation between $\mathrm{MFH}$ and $\mathrm{BZ}$ is due to denaturation of proteins and their subsequent aggregation caused by the heat dissipated by the magnetic nanoparticles in MFH. Future studies will be focused on exploring the mechanisms of potentiation between $\mathrm{MFH}$ and $\mathrm{BZ}$ and translation to animal models.

\section{Acknowledgments}

This work was supported by the US National Science Foundation UPRM CREST (HRD-0833112), the PR Institute for Functional Nanomaterials (EPS-1002410), and the US National Institutes of Health (U54 CA 96300/U54 CA 96297).

\section{Disclosure}

The authors report no conflicts of interest in this work.

\section{References}

1. Wolf DH, Hilt W. The proteasome: a proteolytic nanomachine of cell regulation and waste disposal. Biochim Biophys Acta. 2004; 1695(1-3):19-31.

2. Miller J, Gordon C. The regulation of proteasome degradation by multi-ubiquitin chain binding proteins. FEBS Lett. 2005;579(15): 3224-3230.

3. Crews CM. Feeding the machine: mechanisms of proteasomecatalyzed degradation of ubiquitinated proteins. Curr Opin Chem Biol. 2003;7(5):534-539.

4. Kim HM, Yu Y, Cheng Y. Structure characterization of the $26 \mathrm{~S}$ proteasome. Biochim Biophys Acta. 2011;1809(2):67-79.

5. Frankland-Searby S, Bhaumik SR. The $26 \mathrm{~S}$ proteasome complex: an attractive target for cancer therapy. Biochim Biophys Acta. 2012;1825(1):64-76.

6. Wu WKK, Cho CH, Lee CW, et al. Proteasome inhibition: a new therapeutic strategy to cancer treatment. Cancer Lett. 2010;293(1):15-22.

7. Farras R, Bossis G, Andermarcher E, Jariel-Encontre I, Piechaczyk M. Mechanisms of delivery of ubiquitylated proteins to the proteasome: new target for anti-cancer therapy? Crit Rev Oncol Hematol. 2005;54(1): 31-51.

8. Mateos MV, San Miguel JF. Bortezomib in multiple myeloma. Best Pract Res Clin Haematol. 2007;20(4):701-715.

9. Codony-Servat J, Tapia MA, Bosch M, et al. Differential cellular and molecular effects of bortezomib, a proteasome inhibitor, in human breast cancer cells. Mol Cancer Ther. 2006;5(3):665-675.

10. Mujtaba T, Dou QP. Advances in the understanding of mechanisms and therapeutic use of bortezomib. Discov Med. 2011;12(67):471-480.

11. $\mathrm{Xu} \mathrm{H,} \mathrm{Ju} \mathrm{D,} \mathrm{Jarois} \mathrm{T,} \mathrm{Xie} \mathrm{Y.} \mathrm{Diminished} \mathrm{feedback} \mathrm{regulation} \mathrm{of} \mathrm{pro-}$ teasome expression and resistance to proteasome inhibitors in breast cancer cells. Breast Cancer Res Treat. 2008;107(2):267-274. 
12. Ling X, Calinski D, Chanan-Khan AA, Zhou M, Li F. Cancer cell sensitivity to bortezomib is associated with survivin expression and p53 status but not cancer cell types. J Exp Clin Cancer Res. 2010;29:8.

13. Loeffler-Ragg J, Mueller D, Gamerith G, et al. Proteomic identification of aldo-keto reductase AKR1B10 induction after treatment of colorectal cancer cells with the proteasome inhibitor bortezomib. Mol Cancer Ther. 2009;8(7):1995-2006.

14. de Wilt LH, Jansen G, AssarafYG, et al. Proteasome-based mechanisms of intrinsic and acquired bortezomib resistance in non-small cell lung cancer. Biochem Pharmacol. 2012;83(2):207-217.

15. Smith AJ, Dai H, Correia $\mathrm{C}$, et al. Noxa/Bcl-2 protein interactions contribute to bortezomib resistance in human lymphoid cells. $J$ Biol Chem. 2011;286(20):17682-17692.

16. Shringarpure R, Catley L, Bhole D, et al. Gene expression analysis of B-lymphoma cells resistant and sensitive to bortezomib. Br J Haematol. 2006;134(2):145-156.

17. Vanakoski J, Seppala T. Heat exposure and drugs. A review of the effects of hyperthermia on pharmacokinetics. Clin Pharmacokinet. 1998;34(4):311-322.

18. Neznanov N, Komarov AP, Neznanova L, Stanhope-Baker P, Gudkov AV. Proteotoxic stress targeted therapy (PSTT): induction of protein misfolding enhances the antitumor effect of the proteasome inhibitor bortezomib. Oncotarget. 2011;2(3):209-221.

19. Milani V, Lorenz M, Weinkauf M, et al. Combination of hyperthermia and bortezomib results in additive killing in mantle cell lymphoma cells. Int J Hyperthermia. 2009;25(4):262-272.

20. Roti Roti JL. Cellular responses to hyperthermia (40-46 degrees C): cell killing and molecular events. Int J Hyperthermia. 2008;24(1):3-15.

21. Wust P, Hildebrandt B, Sreenivasa G, et al. Hyperthermia in combined treatment of cancer. Lancet Oncol. 2002;3(8):487-497.

22. Habash RW, Bansal R, Krewski D, Alhafid HT. Thermal therapy, part 2: hyperthermia techniques. Crit Rev Biomed Eng. 2006;34(6):491-542.

23. Banerjee R, Katsenovich Y, Lagos L, McIintosh M, Zhang X, Li CZ Nanomedicine: magnetic nanoparticles and their biomedical applications. Curr Med Chem. 2010;17(27):3120-3141.

24. Latorre M, Rinaldi C. Applications of magnetic nanoparticles in medicine: magnetic fluid hyperthermia. P R Health Sci J. 2009;28(3): 227-238.

25. Rodriguez-Luccioni HL, Latorre-Esteves M, Mendez-Vega J, et al. Enhanced reduction in cell viability by hyperthermia induced by magnetic nanoparticles. Int J Nanomedicine. 2011;6:373-380.

26. Lee JS, Rodriguez-Luccioni HL, Mendez J, et al. Hyperthermia induced by magnetic nanoparticles improves the effectiveness of the anticancer drug cis-diamminedichloroplatinum. J Nanosci Nanotechnol. 2011;11(5):4153-4157.
27. Alvarez-Berrios MP, Castillo A, Rinaldi C, Soto O, Rinaldi C, Torres-Lugo M. Hyperthermic potentiation of cisplatin by magnetic nanoparticle heaters is correlated with an increase in cell membrane fluidity. Int J Nanomedicine. 2013;8:1-11.

28. Herrera AP, Barrera C, Rinaldi C. Synthesis and functionalization of magnetite nanoparticles with aminopropylsilane and carboxymethyldextran. J Mater Chem. 2008;18(31):3650-3654.

29. Creixell M, Bohorquez AC, Torres-Lugo M, Rinaldi C. EGFR-targeted magnetic nanoparticle heaters kill cancer cells without a perceptible temperature rise. ACS Nano. 2011;5(9):7124-7129.

30. Pajonk F, van Ophoven A, McBride WH. Hyperthermia-induced proteasome inhibition and loss of androgen receptor expression in human prostate cancer cells. Cancer Res. 2005;65(11):4836-4843.

31. Sapareto SA, Dewey WC. Thermal dose determination in cancer therapy. Int J Radiat Oncol Biol Phys. 1984;10(6):787-800.

32. Bodell WJ, Cleaver JE, Roti Roti JL. Inhibition by hyperthermia of repair synthesis and chromatin reassembly of ultraviolet-induced damage to DNA. Radiat Res. 1984;100(1):87-95.

33. Cummings M. Increased c-fos expression associated with hyperthermiainduced apoptosis of a Burkitt lymphoma cell line. Int J Radiat Biol. 1995;68(6):687-692.

34. Hildebrandt B, Wust $\mathrm{P}$, Ahlers $\mathrm{O}$, et al. The cellular and molecular basis of hyperthermia. Crit Rev Oncol Hematol. 2002;43(1):33-56.

35. Domenech M, Marrero-Berrios I, Torres-Lugo M, Rinaldi C. Lysosomal membrane permeabilization by targeted magnetic nanoparticles in alternating magnetic fields. ACS Nano. 7(6):5091-5101.

36. Oerlemans R, Franke NE, Assaraf YG, et al. Molecular basis of bortezomib resistance: proteasome subunit $\hat{I}^{2} 5$ (PSMB5) gene mutation and overexpression of PSMB5 protein. Blood. 2008;112(6) 2489-2499.

37. Minderman H, Zhou Y, O’Loughlin K, Baer M. Bortezomib activity and in vitro interactions with anthracyclines and cytarabine in acute myeloid leukemia cells are independent of multidrug resistance mechanisms and p53 status. Cancer Chemother Pharmacol. 2007;60(2):245-255.

38. Williamson MJ, Silva MD, Terkelsen J, et al. The relationship among tumor architecture, pharmacokinetics, pharmacodynamics, and efficacy of bortezomib in mouse xenograft models. Mol Cancer Ther. 2009;8(12):3234-3243.

39. Zheng B, Zhou R, Gong Y, Yang X, Shan Q. Proteasome inhibitor bortezomib overcomes P-gp-mediated multidrug resistance in resistant leukemic cell lines. Int J Lab Hematol. 2012;34(3):237-247.
International Journal of Nanomedicine

\section{Publish your work in this journal}

The International Journal of Nanomedicine is an international, peerreviewed journal focusing on the application of nanotechnology in diagnostics, therapeutics, and drug delivery systems throughou the biomedical field. This journal is indexed on PubMed Central,

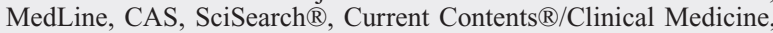

\section{Dovepress}

Journal Citation Reports/Science Edition, EMBase, Scopus and the Elsevier Bibliographic databases. The manuscript management system is completely online and includes a very quick and fair peer-review system, which is all easy to use. Visit http://www.dovepress.com/ testimonials.php to read real quotes from published authors. 